\title{
Temperature Rise during Resin Composite Polymerization under Different Ceramic Restorations
}

\author{
Isa Yondem a \\ Subutay Han Altintas ${ }^{b}$ \\ Aslihan Usumez
}

\section{ABSTRACT}

Objectives: The purpose of this study was to measure temperature increase induced by various light polymerizing units during resin composite polymerization beneath one of three types of ceramic restorations.

Methods: The resin composite (Variolink II) was polymerized between one of three different ceramic specimens (zirconium oxide, lithium disilicate, feldspathic) (diameter $5 \mathrm{~mm}$, height $2 \mathrm{~mm}$ ) and a dentin disc (diameter $5 \mathrm{~mm}$, height $1 \mathrm{~mm}$ ) with a conventional halogen light, a high intensity halogen light, or an LED unit. The temperature rise was measured under the dentin disc with a J-type thermocouple wire connected to a data logger. Ten measurements were carried out for each group. The difference between the initial and highest temperature readings was taken and the 10 calculated temperature changes were averaged to determine the mean value in temperature rise. Two way analysis of variance (ANOVA) was used to analyze the data (polymerizing unit, ceramic brand) for significant differences. The Tukey HSD test was used to perform multiple comparisons ( $\alpha=.05)$.

Results: Temperature rise did not vary significantly depending on the light polymerizing unit used $(P=.16)$, however, the type of ceramic system showed a significant effect on temperature increases $(P<.01)$. There were no statistically significant differences between lithium disilicate and feldspathic ceramic systems ( $P$ >.05); in comparison, the resin composite polymerized under the zirconium oxide ceramic system induced a significantly lower temperature increase than the other ceramic systems tested $(P<.05)$

Conclusions: The resin composite polymerized beneath zirconium oxide ceramic system induced significantly smaller temperature changes. The maximal temperature increase detected in all groups in this study was not viewed as critical for pulpal health. (Eur J Dent 2011;5:305-309)

Key words: Resin composite; Temperature; Ceramic restoration; Zirconium oxide.

Assist. Professor, Department of Prosthodontics, Faculty of Dentistry, Selcuk University, Konya, Turkey.

b Assist. Professor, Department of Prosthodontics, Faculty of Dentistry, Karadeniz Technical University, Trabzon, Turkey.

Professor, Department of Prosthodontics,

Faculty of Dentistry, Gaziantep University, Gaziantep, Turkey.
Corresponding author: Dr. Isa Yondem Selcuk University, Faculty of Dentistry, Department of Prosthodontics Selcuklu 42079, Campus, Konya, Turkey. Phone: +90 332 2410041/1190 Fax: +903322410062

E-mail: isayondemayahoo.com 


\section{INTRODUCTION}

During the past few years, dental patients have increasingly demanded tooth-colored restorations. Predictable and esthetic nonmetal, fixed partial dentures are desired by dentists and patients. ${ }^{1}$ In most situations, placement of ceramic restorations using dual-polymerizing composite fulfills the esthetic requirements and minimizes the disadvantage of polymerization shrinkage. These composites are generally hybrid-type composites, based on Bis-GMA chemistry. Normally for resin composites, polymerization is initiated both chemically and by visible light, using a wavelength of $400-500 \mathrm{~nm}^{2}$

Until recently, light emitted from a halogen light bulb has been used to polymerize the resin composite. These types of light sources usually operate at light intensities between 400 and 800 $\mathrm{mW} / \mathrm{cm}^{2}$ and polymerize the composite resin filling material within 40 seconds. Halogen bulbs produce light when electrical energy heats a small tungsten filament to high temperatures. Despite their common use in dentistry, halogen bulbs have several disadvantages. The basic principle of light conversion by this technique is claimed to be inefficient, as the light power output is less than 1 percent of the consumed electrical power; and, as they have a limited effective lifetime of approximately 100 hours, due to degradation of bulb components by the high heat generated.

A solid-state light emitting diode (LED) technology was proposed in 1995 for the polymerization of light-polymerized dental materials, to overcome the shortcomings of halogen visible light-polymerizing units. ${ }^{2}$ The LEDs use junctions of doped semiconductors to generate light instead of the hot filaments used in halogen bulbs. ${ }^{3}$ LEDs have a lifetime of over 10,000 hours and undergo little degradation of output over this time. LEDs require no filters to produce blue light, are resistant to shock and vibration, and take little power to operate. ${ }^{4}$ LEDs' longer lifespan and more consistent light output compared with halogen bulb technology show promise for dental applications. ${ }^{5}$

The polymerization of light polymerizing resin composites produces a temperature increase, caused by both the exothermic reaction process and the energy absorbed during irradiation..$^{6-10}$ The polymerizing units themselves are capable of creating a temperature rise up to $12^{\circ} \mathrm{C}$ with the use of visible light polymerized resin composites. ${ }^{10}$ This has been shown to be a major source of heat which may damage the pulp. ${ }^{7}$ Light polymerizing with high energy output causes significantly higher pulp chamber temperature changes as compared to conventional halogen polymerizing light. ${ }^{11,12}$

Yttria stabilized tetragonal zirconia (Y-TZP) is gaining recognition as a candidate material in dentistry, due to its mechanical properties. It is currently used as a core material in full-ceramic dental restorations, ${ }^{13}$ implant superstructures and orthodontic brackets. ${ }^{14}$ Compared to other dental ceramics, the superior mechanical properties of Y-TZP are due to the transformation toughening mechanism, similar to that exploited in quenched steel. $\mathrm{ZrO}_{2}$ is a polymorphic material that has three allotropes: the monoclinic phase is stable up to $1170^{\circ} \mathrm{C}$, where it transforms into the tetragonal phase, which is stable up to $2370^{\circ} \mathrm{C}$, and the cubic phase exists up to the melting point at $2680^{\circ} \mathrm{C} . .^{15}$

The total duration of temperature rise and storage of harmful heat is important for pulpal health. 17,18 Zach and Cohen ${ }^{16}$ reported irreversible pulpal damage in $15 \%$ of rhesus monkeys for temperature elevations of $5.6^{\circ} \mathrm{C}, 60 \%$ for temperature elevations of $11^{\circ} \mathrm{C}$, and $100 \%$ for temperature elevations of $16.6^{\circ} \mathrm{C}$.

The purpose of this in vitro study was to measure the temperature rise induced by selected polymerizing units: conventional halogen (QTH), high intensity halogen (HQTH), and LED units during resin composite polymerization under one of 3 different ceramic restorations: 1) lithium disilicate based ceramic (LDBC), 2) feldspathic ceramic (FC), and 3) zirconium oxide based ceramic (ZBC). The hypothesis tested assumed there was no difference in temperature rise under dentin disc when the resin composite was polymerized beneath one of the three different ceramic systems with three different light sources.

\section{MATERIALS AND METHODS}

To simulate resin composite polymerization during the luting process of an inlay or onlay, 3 polymerizing units were evaluated: QTH, HQTH, LED unit. Manufacturers' details, light intensities, applied polymerization time and other pertinent information are listed in Table 1.

Ceramic restoration, resin composite and dentin disc preparation

The ceramic specimens used in this study were of $2 \mathrm{~mm}$ thickness and $5 \mathrm{~mm}$ in diameter. The LDBC (IPS Empress 2, color 300, Ivoclar, Schaan, Liechtenstein) specimen was composed of $1 \mathrm{~mm}$ thick framework material and $1 \mathrm{~mm}$ thick layering material. By using a slow speed saw Ilsomet, 
Buehler, Evanston, IL, USA), a $1 \mathrm{~mm}$ disc was prepared from the ZBC block (Cercon, color A2, Degudent, Hanau, Germanyl under water cooling and then sintered. A $1 \mathrm{~mm}$ thick layering material (Cercon, Degudent) was prepared in accordance with the manufacturer's instructions. For the FC system, a $2 \mathrm{~mm}$ thick disc was prepared from the FC block (Vita Mark II, color A2, Vident Inc, Brea, CA) using the same slow speed saw (Isomet, Buehler).

By using the same slow speed saw, the occlusal enamel portion of a mandibular third molar was removed to denude the dentin by sectioning it perpendicular to the long axis of the tooth. A dentin disc of $5 \mathrm{~mm}$ diameter and $1 \mathrm{~mm}$ height was prepared.

A commercially available resin composite, Variolink II (Vivadent, Ivoclar, Schaan, Liechtenstein), was selected for the present study. To make the resin composite dual-polymerizing, the light-polymerizing component (Variolink II Base: Braun, 340/A4, Lot no: E132643, Vivadent) was mixed with a catalyst (Variolink II Catalyst: low viscosity type, 210/A3, Lot no: E16157, Vivadent) in accordance with the manufacturers' instructions

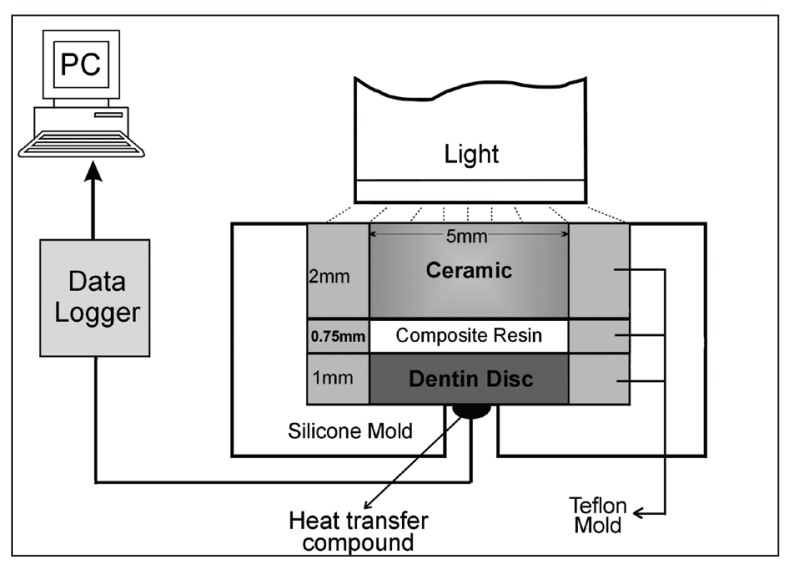

Figure 1. Schematic drawing of experimental setup showing the temperature measurement during polymerization of the composite resin composite through the ceramic specimen.

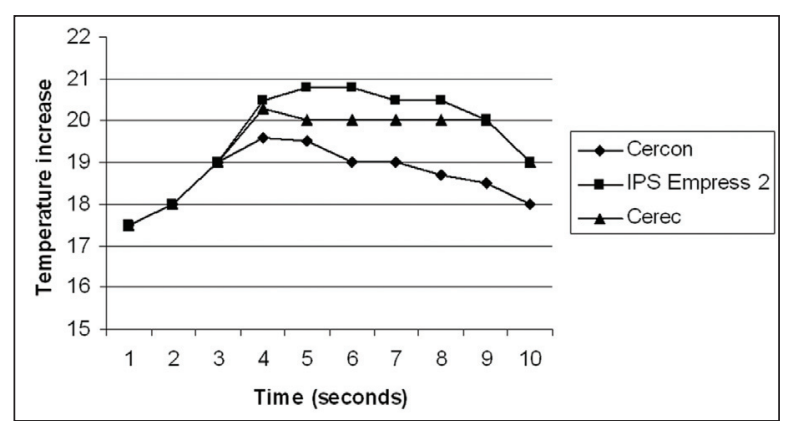

Figure 2. Representative temperature change graph for the high intensity halogen light. The values used in the graph were acquired using values of 10 data points which were also averages of 10 repeated measurements. and then placed in a $5 \mathrm{~mm}$ diameter and $0.75 \mathrm{~mm}$ Teflon mold, which was then brought into contact with the dentin disc.

Temperature measurement

The temperature rise was measured under a dentin disc to simulate the temperature rise in the pulp, and composite resin was applied and polymerized between the ceramic specimen and the dentin disc. A silicone mold was prepared as a supporting structure for the dentin / resin composite / ceramic complex (Figure 1). The light tip of the polymerizing units was centered on the ceramic restoration without any distance. No strip band was used during placement or light polymerizing of the composite resin between dentin and ceramic restoration.

A silicone heat-transfer compound (ILC P/N 213414, Wakefield Engineering, MA, USA) was applied under the dentin disc. A J-type thermocouple wire with 0.36 inc diameter 10 mega Engineering, Inc, Stamford, CT, USAl was connected to a data logger (XR440-M Pocket Logger, Pace Scientific, NC, USAl during application of polymerizing lights. $^{19}$

The sampling rate of the data logger was 2 seconds. The collected data were monitored in real time and transferred to a computer. The data was available in both tabular and graphic form. Temperature changes were recorded every two seconds from the start of polymerization, for approximately 10-20 seconds until the temperature started to decrease.

The light outputs of the polymerizing units were measured before each testing procedure using a digital radiometer (built-in radiometer on Optilux 501 unit). Following measurement of the light output, the test was repeated ten times for each polymerizing unit. The difference between the initial temperature and the highest temperature reading was recorded. The test was repeated 10 times and

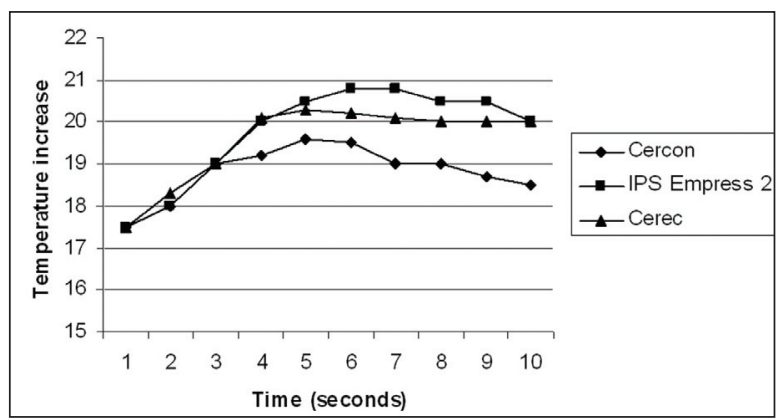

Figure 3. Representative temperature change graph for the conventional halogen light. The values used in the graph were acquired using values of 10 data points which were also averages of 10 repeated measurements. 
the 10 calculated temperature changes were averaged to determine the mean value in temperature rise.

All experimental trials were performed using the same ceramic restoration specimen and dentin disc. Acid-etching, enamel or dentin bonding was not applied, in order to facilitate easy removal of the resin composite after polymerization. The dentin disc was checked for resin remnants using a stereomicroscope (SZTP; Olympus, Tokyo, Japan) at 22X magnification and was cleaned with a scaler, when necessary, and a dentin disc.

The test results were entered into an Excel (Microsoft, Seattle, WAl spread sheet for calculation of descriptive statistics. The values determined for different ceramic specimens and polymerizing units were compared using two way analysis of variance (ANOVA) at a preset alpha of 0.05 .

\section{RESULTS}

Temperature rise did not vary significantly according to the light polymerizing unit $(Q T H, H Q T H$, LED unit) used ( $P=.16)$. However, the type of ceramic system (LDBC, ZBC, FC) showed a significant effect on temperature increases $(P<.01)$ (Table 2).

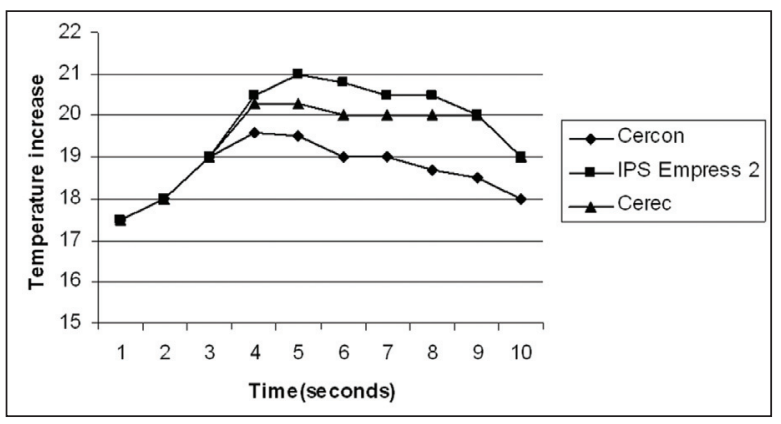

Figure 4. Representative temperature change graph for the LED light. The values used in the graph were acquired using values of 10 data points which were also averages of 10 repeated measurements.
The resin composite polymerized under the ZBC system induced a significantly lower $\left(2.3 \pm 0.3^{\circ} \mathrm{C}\right)$ temperature increase than the other ceramic systems tested $(P<.05)$; there were no statistically significant differences between the $\operatorname{LDBC}\left(3.4 \pm 0.4^{\circ} \mathrm{C}\right)$ and $\mathrm{FC}$ systems $\left(3 \pm 0.6^{\circ} \mathrm{C}\right)$ (P>.05) (Figures 2, 3 and 4).

\section{DISCUSSION}

The results did not support the research hypothesis that there was no significant difference in temperature rise under the dentin disc when resin composite was polymerized beneath one of the 3 different ceramic systems with one of the 3 light sources. Temperature rise did not vary significantly depending on the light polymerizing unit used; however, type of ceramic system showed a significant effect of on temperature increases. The resin composite polymerized beneath the ZBC system induced a significantly lower temperature increase than the other ceramic systems tested. This may be due to the different compositions of the ceramic systems and the high density of the zirconium oxide ceramic system. ${ }^{15}$

For this comparative study, the same dentin disc was used to simulate the effect of residual dentin. This procedure was followed to eliminate any possible histochemical and/or structural variables of teeth that may manifest in differences in the thermal conductivity and specific heat.

The resin composite was placed between a ceramic restoration and a dentin disc without any bonding agent. It was therefore possible to easily remove the polymerized material during repeated measurements in the 9 experimental groups without alteration of the dentin disc. It could be supposed that heat transfer to the thermocouple wire would be diminished, and the data provided from temperature measurements may be lower than

Table 1. Visible light polymerizing units studied.

\begin{tabular}{lccccc}
\hline Brand & Type of unit & $\begin{array}{c}\text { Output of light tip } \\
\left(\mathrm{mW} / \mathrm{cm}^{2}\right)\end{array}$ & $\begin{array}{c}\text { Diameter of } \\
\text { the tip }(\mathrm{mm})\end{array}$ & $\begin{array}{c}\text { Applied polymerization } \\
\text { time }(\mathrm{s})\end{array}$ & Manufacturer \\
\hline Hilux & $\begin{array}{c}\text { Conventional } \\
\text { Halogen } \\
\text { High Intensity } \\
\text { Halogen }\end{array}$ & 450 & 10 & 40 & $\begin{array}{c}\text { Express Dental Products, Toronto, } \\
\text { Canada }\end{array}$ \\
Optilux 501 & 810 & 8 & 20 & Kerr, Danbury, CT, USA \\
Elipar Freelight 2 & LED & 1000 & 8 & 20 & 3M Espe, St. Paul, MN, USA \\
\hline
\end{tabular}

Table 2. Two way analysis of variance.

\begin{tabular}{lccccc}
\hline & SS & DF & MS & F & \\
\hline Polymerizing unit & 1.31 & 2 & 0.6 & 1.88 & 0.16 \\
Ceramic system & 18 & 2 & 9 & 26.13 & 0.00 \\
Polymerizing unit * Ceramic system & 1.54 & 4 & 0.4 & 1.15 & 0.33 \\
\hline
\end{tabular}


that actually occurring if the resin composite /dentin interface had been maintained. However, the results of the preliminary experiments did not indicate statistically significant differences between measurements of pulpal chamber temperature rise during resin composite polymerization, either with or without previously applied bonding agent. ${ }^{12}$

A temperature rise of $5.5^{\circ} \mathrm{C}$ has been reported to damage the pulp. ${ }^{16}$ The resin composite polymerized under the ZBC system caused a temperature rise of $2.3^{\circ} \mathrm{C}$, whereas $3.4^{\circ} \mathrm{C}$ was recorded for LDBC and $3^{\circ} \mathrm{C}$ was recorded for FC. Considering these values, the maximal temperature increase detected for all polymerizing units tested in this study was not viewed as critical.

The temperature increases reported in this study are smaller than those of a previous study. ${ }^{17}$ This may be a result of greater distance from light tip to thermocouple wire and possible insulation effect of the ceramic disc used.

Furthermore, the temperature values measured in this study cannot be directly compared to temperature changes in-vivo. This is because the experimental setup of this study did not consider heat conduction within the tooth during in situ composite resin polymerization due to the effect of blood circulation in the pulp chamber. ${ }^{18}$

\section{CONCLUSIONS}

Measurements of temperature increase during composite resin polymerization under in vitro ceramic restoration indicated that:

- Light polymerizing under ZBC (Cercon) system induced the smallest temperature increase compared to other ceramic systems.

- The maximal temperature increase detected in all groups in this study was not viewed as critical for pulpal health.

\section{REFERENCES}

1. Stahl F, Ashworth SH, Jandt KD, Mills RW. Light emitting diode (LED) polymerization of dental composites: flexural properties and polymerization potential. Biomaterials 2000;21:1379-1385.

2. Mills RW, Jandt KD, Ashworth SH. Dental composite depth of cure with halogen and blue light emitting diode technology. Br Dent J 1999;186:388-391.

3. Nakamura S, Mukai T, Senoh M. Candela-class high brightness InGaN/AlGaN double heterostructure blue-lightemitting diodes. Appl Phys Lett 1994;64:16807-16813.
4. Oesterle LJ, Newman SM, Shellhart WC. Rapid curing of bonding composite with a xenon plasma arc light. Am J Orthod Dentofacial Orthop 2001;119:610-616.

5. Dunn WJ, Taloumis LJ. Polymerization of orthodontic resin cement with light-emitting diode curing units. Am J Orthod Dentofacial Orthop 2002;122:236-241.

6. Haitz RH, Craford MG, Wiessman RH. Handbook of optics; vol 2. New York: McGraw Hill p. 1995;12:1-9.

7. Lloyd $\mathrm{CH}$, Joshi AE, McGlynn E. Temperature rises produced by light sources and composites during curing. Dent Mater 1986;2:170-177.

8. Masutani S, Setcos JC, Schnell RJ, Phillips RW. Temperature rise during polymerization of visible light activated resins. Dent Mater 1988;4:174-178.

9. McCabe JF. Cure performance of light -activated composites by differential thermal analysis. Dent Mater 1985;1:231234.

10. Smail SRJ, Patterson CJW, McLundie AC, Strang R. In vitro temperature rise during visible light curing of a lining material and a posterior composite. J Oral Rehabil 1988; 15:361-366.

11. Weerakoon AT, Meyers IA, Symons AL, Walsh LJ. Pulpal heat changes with newly developed resin photopolymerisation systems. Aust Endod J 2002;28:108-111.

12. Hannig M, Bott B. In-vitro pulp chamber temperature rise during composite resin polymerization with various lightcuring sources. Dent Mater 1999;15:275-281.

13. Paul S, Schärer P. Adhäsivaufbauten für Vollkeramik-Kronen. Schweiz Monatsschr Zahnmed 1996;368-374.

14. Keith O, Kusy RP, Whitley JQ. Zirconia brackets: an evaluation of morphology and coefficients of friction. Am J Orthod Dentofacial Orthop 1994;106:605-614.

15. Subbarao EC. Zirconia-an overview. Adv Ceram 1981:1-24.

16. Zach L, Cohen C. Pulp response to externally applied heat. Oral Surg Oral Med Oral Pathol 1965;19:515-530.

17. Pohto M, Scheinin A. Microscopic observations on living dental pulp. Acta Odontol Scand 1958;16:303-327.

18. Raab WHM. Temperature changes in pulpal microcirculation. Proc Finn Dent Soc 1992;88:469-479.

19. Usumez A, Ozturk N. Temperature rise during resin cement polymerization under a ceramic restoration: Effect of type of curing units. Int J Prosthodont 2004;17:200-204. 